\title{
ROLE OF COMORBID RISK FACTORS OF TUBERCULOSIS IN BRONCHIAL ARTERY EMBOLISATION FOR MANAGING MASSIVE HAEMOPTYSIS
}

\author{
P. V. Kalyan Kumar1, Ramakrishna Gorantla², Ramakrishna Rachakonda ${ }^{3}$ \\ ${ }^{1}$ Assistant Professor, Department of Pulmonary Medicine, Katuri Medical College, Guntur, Andhra Pradesh. \\ ${ }^{2}$ Associate Professor, Department of General Medicine, Katuri Medical College, Guntur, Andhra Pradesh. \\ ${ }^{3}$ Professor, Department of Pulmonary Medicine, Katuri Medical College, Guntur, Andhra Pradesh.
}

\section{ABSTRACT}

\section{BACKGROUND}

Among the multiple causes of haemoptysis, active tuberculosis (TB), chronic inflammatory lung diseases due to bronchiectasis, aspergilloma within a chronic sarcoid or tuberculous cavity are the most common cause of haemoptysis in developing countries. Several diseases increase the risk of tuberculosis causing increased morbidity and mortality among these patients.

The following study was intended to evaluate the role of comorbid risk factors in bronchial artery embolisation (BAE) for managing haemoptysis.

\section{MATERIALS AND METHODS}

282 patients who presented with massive haemoptysis were included in the study, 141 over a period of 2 years from April 2012 to April 2014. Further followup of all the patients for 2 years from April 2014 to April 2016 by dividing the patients based on tuberculosis and comorbid risk factors. Recurrent bleeding and mortality were evaluated among the patients.

\section{RESULTS}

55 patients $(40 \%)$ with tuberculosis, $28.3 \%$ of patients with bronchiectasis and fibrocavitary lesion of lung, $7.8 \%$ of patients with aspergilloma underwent BAE. Comorbid risk factors mainly were DM in $15.6 \%$ and HIV in $9.9 \%$ of patients. Haemoptysis free survival rate in TB patients along with comorbid risk factors were $64.4 \%, 55.2 \%$ and $41.2 \%$ in 6,12 and 24 months respectively. Whereas in non-tuberculous conditions it was $81.3 \%, 77.1 \%$ and $68.1 \%$ in 6,12 and 24 months respectively and in tuberculosis alone without any risk factors it was $98.1 \%, 91.2 \%$ and $88.1 \%$ in 6,12 and 24 months respectively which showed a statistical significance $(p=0.05)$. Mortality rate was significantly high in TB along with comorbid risk conditions group when compared to the rest of the groups $(\mathrm{p}=0.05)$.

\section{CONCLUSION}

Prognosis of the TB patients without comorbid risk factors were good when compared to TB along with risk factors for BAE for massive haemoptysis. The risk factors namely diabetes mellitus (DM), human immunodeficiency virus (HIV), chronic liver diseases, chronic renal diseases and coronary artery diseases not only play an important in the activation of latent infection, but also causes increased mortality in these patients. So these risk factors can also be considered as comorbidities in these patients increasing the risk of recurrent haemoptysis and mortality of patients undergoing BAE for massive haemoptysis.

\section{KEYWORDS}

Bronchial artery embolisation (BAE), massive haemoptysis, pulmonary tuberculosis (TB), diabetes mellitus (DM), human immunodeficiency virus (HIV).

HOW TO CITE THIS ARTICLE: Kumar PVK, Gorantla R, Rachakonda R. Role of comorbid risk factors of tuberculosis in bronchial artery embolisation for managing massive haemoptysis. J. Evolution Med. Dent. Sci. 2017;6(81):5717-5723, DOI: $10.14260 /$ jemds/2017/1240

\section{BACKGROUND}

\section{Definition of Haemoptysis}

Haemoptysis or the expectoration of blood from the lower respiratory tract ${ }^{1,2}$ can range from blood-streaking of sputum to the presence of gross blood in the absence of any accompanying sputum.

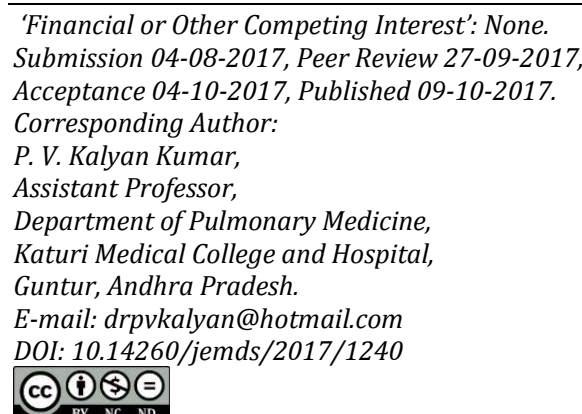

The definition of massive haemoptysis varies widely in the literature from $200 \mathrm{~mL}$ to $1000 \mathrm{~mL} / 24 \mathrm{hrs}, 3,4$ but the expectoration of $\geq 600 \mathrm{~mL}$ in $24 \mathrm{hrs}$. is what most authors use in clinical reports to define massive haemoptysis. ${ }^{5}$

It is estimated that $400 \mathrm{~mL}$ of blood in the alveolar space is sufficient to cause significant hindrance to the oxygen transfer, ${ }^{6}$ although only minor changes in the vital signs will be noted for the same amount of blood loss. ${ }^{7}$

Massive haemoptysis is usually a sign of an underlying chronic disease. ${ }^{8}$

Active tuberculosis (TB) continues to be the leading cause of haemoptysis worldwide. ${ }^{9}$ In some cases, 'a cause' cannot be found and is termed idiopathic or cryptogenic haemoptysis. It is a diagnosis of exclusion and is reported to be responsible for $3 \%-42 \%$ of haemoptysis episodes, particularly in smokers. ${ }^{10}$ 
Documented mortality rates following surgical intervention vary between $7.1 \%$ and $18.2 \%$, but increase to $40 \%$ in certain emergency conditions. ${ }^{11}$ Larger number of patients with haemoptysis are not suitable candidates for surgery due to pre-existing comorbidities and poor respiratory reserve. However, surgery remains the treatment of choice for the treatment of massive haemoptysis caused by iatrogenic pulmonary artery rupture, trauma to chest and aspergilloma resistant to other treatment options. ${ }^{12}$ BAE has become a well-established interventional vascular technique for the management of massive and recurrent haemoptysis. ${ }^{13,14}$ The survey by the American College of Chest Physicians showed that a higher proportion of chest physicians favoured interventional radiology over either conservative or surgical management. 15

BAE of bronchial and non-bronchial systemic arteries is now a well-known procedure for the control of massive and recurrent haemoptysis. Immediate control of haemoptysis is achieved in $73 \%-99 \%$ of treated patients. However, recurrent haemoptysis is common, occurring in $10 \%$ $55 \% \cdot 14,15,16$

Even though BAE in TB patients has been studied previously, ${ }^{17,18}$ these studies have limited number of patients with tuberculosis as the aetiological factor for massive haemoptysis and the results have not been sufficient to address the role of BAE in pulmonary tuberculosis patients having comorbid risk factors. Our study was intended to evaluate recurrence of haemoptysis and mortality of the patients undergoing BAE.

The burden of tuberculosis and cardiovascular disease (CVD) are rapidly increasing in low- and middle-income countries like India. ${ }^{19}$ Many public health programs are challenged with the overlapping tuberculosis and CVD epidemics. ${ }^{20}$ Recent epidemiologic work has shown that the risk of cardiovascular diseases among the persons who develop tuberculosis is higher than in persons without a history of tuberculosis, even several years after recovery from tuberculosis. ${ }^{21}$

\section{Aims and Objectives}

The present study was intended to evaluate the role of various co-morbid risk factors in bronchial artery embolisation (BAE) for managing haemoptysis.

\section{MATERIALS AND METHODS}

It is a retrospective study intended to evaluate the role of comorbid risk factors in bronchial artery embolisation (BAE) for managing haemoptysis among the three cohorts namely-

1) Patients suffering from tuberculosis alone without any comorbid risk factors (TB group).

2) Patients having comorbid risk factors along with tuberculosis (TB + comorbid).

3) Patients having non-tuberculosis pulmonary disease (Non-TB).

\section{Study Design}

The following study is a retrospective observational and analytical cohort study for two years among the patients admitted for massive haemoptysis undergoing bronchial artery embolisation.

\section{Study Group}

Out of the 282 patients who presented with massive haemoptysis, 141 patients were included in the study after fulfilling the inclusion criteria from April 2012 to April 2014. Followup of patients for two years from April 2014 to April 2016 were done after undergoing bronchial artery embolisation.

The analytical component of the study aims to determine if tuberculosis infection adversely affected the outcome of the procedure.

\section{Inclusion Criteria}

1) Patients from whom biological specimen was positive by smear microscopy, culture or WHO-approved rapid diagnostic test (such as Xpert MTB/RIF) for the diagnosis of pulmonary tuberculosis.

2) Patients in whom the first and second attempts of bronchial artery embolisation were done.

3) Patients in whom surgical intervention is not possible for the following disease conditions like lung abscess, bronchiectasis, bronchogenic carcinoma, cystic fibrosis or pneumonia.

\section{Exclusion Criteria}

1) Third or subsequent bronchial artery embolisation attempted for the same patient.

2) Multidrug resistant tuberculosis and extensive drug tuberculosis patients (MDRTB/ XDR-TB).

3) Patient less than 14 years old.

\section{Statistical Analysis}

Data analysis was done by SPSS 24.0 (SPSS, IBM, USA) were used for statistical analysis. Chi-square test was used for categorical data for comparing control of bleeding (yes) and no control of bleeding (no) among the three treatment arms.

Cumulative recurrent haemoptysis free rate and cumulative survival rate were evaluated individually using a Kaplan-Meier survival analysis. Log-rank test was performed to determine the significance between the three groups. Univariate and multivariate analysis was performed to determine risk factors of recurrent haemoptysis and mortality.

Cox proportional hazard model was used to estimate hazard ratio (HR) for recurrent haemoptysis and mortality between two groups. Multiple variables were calculated in the form of mean value \pm standard deviation. $P$ value less than 0.05 was measured to be statistically significant among the groups.

\section{RESULTS}

Of the 282 patients who presented with massive haemoptysis, 141 patients underwent bronchial artery embolisation (BAE). Majority of the patients (79) (Table 0.5) were male $(56.2 \%)$. The basic demographic properties of the included patients were shown in Table A.

The age of the patients included in our study were between 15 - 70 years with an average of mean age of 46.01 years. The majority of the members were between $50-59$ years of age and minority of the patients were between 14 19 years. Most of the patients $(71.1 \%)$ have $\mathrm{BMI}<18.5 \mathrm{~kg} / \mathrm{m}^{2}$ (Table 0.5 and 1) when compared to patients (28.9\%) having BMI $>18.5 \mathrm{~kg} / \mathrm{m}^{2}$. Among the pulmonary tuberculosis cohort, $3(2.1 \%)$ patients were sputum positive, $2(1.4 \%)$ patients were culture positive and $2(1.4 \%)$ patients were diagnosed based on nucleic acid amplification tests like Xpert MTB (TB NAAT) (Table 1). Diagnoses of $2(1.4 \%)$ patients were done 
based on the radiological findings. Total number of patients suffering with tuberculosis without any comorbid risk factors were 9 (6.3\%); 46 (32.6\%) patients were having comorbid risk factors along with tuberculosis. Among the comorbid risk factors, diabetes mellitus was associated with 22 (15.6\%) patients followed by HIV in $14(9.9 \%)$ patients. Majority of the patients $(55: 40 \%)$ in study were suffering from tuberculosis (TB + TB comorb).
Rest of the $86(60 \%)$ patients were suffering from other non-tuberculous lung diseases, namely fibrocavitary lung disorders and bronchiectasis in 40 (28.3\%), aspergilloma in $11(7.8 \%)$ patients, lung cancer in $9(6.3 \%)$ and pneumonia in $12(8.5 \%)$ patients (Table 1$)$.

\begin{tabular}{|c|c|c|c|c|}
\hline Variables & PTB alone & PTB + Comorbid & Non-Tuberculosis & P value \\
\hline $\begin{array}{l}\text { Gender } \\
\text { Male } \\
\text { Female }\end{array}$ & $\begin{array}{l}05(3.5 \%) \\
04(2.8 \%)\end{array}$ & $\begin{array}{c}25(17.1 \%) \\
2114.8 \%\end{array}$ & $\begin{array}{l}49(34.7 \%) \\
37(26.2 \%)\end{array}$ & $\mathrm{P}>0.05$ \\
\hline Age (Mean) & 43 & 45 & 50 & $P>0.05$ \\
\hline $\begin{array}{c}\text { Body mass index }(\mathrm{m}) \\
>18.5 \\
<18.5 \\
\end{array}$ & $\begin{array}{l}03(2.1 \%) \\
06(4.2 \%)\end{array}$ & $\begin{array}{l}25(17.7 \%) \\
21(14.8 \%) \\
\end{array}$ & $\begin{array}{l}13(09.2 \%) \\
73(51.7 \%) \\
\end{array}$ & $\mathrm{P}<0.05$ \\
\hline $\begin{array}{c}\text { Smokers } \\
\text { Non-smokers/ } \\
\text { ex-smokers } \\
\end{array}$ & $\begin{array}{l}23(16.3 \%) \\
21(14.8 \%)\end{array}$ & $\begin{array}{l}25(17.7 \%) \\
24(17.0 \%)\end{array}$ & $\begin{array}{l}33(23.4 \%) \\
14(09.0 \%)\end{array}$ & $\mathrm{P}<0.05$ \\
\hline
\end{tabular}

\begin{tabular}{|c|c|c|}
\hline \multicolumn{2}{|c|}{ Demographics } & \multirow{3}{*}{$\begin{array}{c}\text { Total Cases } \\
\text { Mean Age 46.01 } \\
79(56.2 \%) \\
62(43.8 \%)\end{array}$} \\
\hline \multicolumn{2}{|c|}{ Age (Years) } & \\
\hline Gender & Male: Female & \\
\hline Body mass index (BMI) & $>18.5:<18.5$ & $\begin{array}{c}41(28.9 \%) \\
100(71.1 \%)\end{array}$ \\
\hline Smoking history & $\begin{array}{l}\text { Smoker/ Ex-smoker } \\
\text { Never smoked }\end{array}$ & $\begin{array}{l}81(57.9 \%) \\
60(42.1 \%)\end{array}$ \\
\hline $\begin{array}{c}\text { Pulmonary } \\
\text { Tuberculosis }(n=9)\end{array}$ & $\begin{array}{c}\text { Sputum positive } \\
\text { Culture positive } \\
\text { TB NAAT positive }\end{array}$ & $\begin{array}{l}3(2.1 \%) \\
2(1.4 \%) \\
2(1.4 \%)\end{array}$ \\
\hline $\begin{array}{c}\text { Tuberculosis }+ \\
\text { Comorbid conditions }(n=46)\end{array}$ & $\begin{array}{c}\text { TB + Immuno.S } \\
\text { TB+DM } \\
\text { TB+HIV } \\
\text { TB+LIVER.D } \\
\text { TB+CVD } \\
\text { TB+CKD }\end{array}$ & $\begin{array}{c}2(1.4 \%) \\
22(15.6 \%) \\
14(9.9 \%) \\
2(1.4 \%) \\
2(1.4 \%) \\
3(2.1 \%)\end{array}$ \\
\hline Non-TB $(n=86)$ & $\begin{array}{c}\text { Fibrocavitary/ Bronchiectasis } \\
\text { Aspergilloma } \\
\text { Lung abscess } \\
\text { Lung cancer } \\
\text { Pneumonia } \\
\text { Others }\end{array}$ & $\begin{array}{c}40(28.3 \%) \\
11(7.8 \%) \\
06(4.2 \%) \\
09(6.3 \%) \\
12(8.5 \%) \\
08(5.6 \%)\end{array}$ \\
\hline & cs of all the Patients included & \\
\hline
\end{tabular}

CVD: Cardiovascular disease, CKD: Chronic kidney disease, NAAT: Nucleic acid amplification test like Xpert MTB.

The events that occurred after the procedure were divided in the following way

In Less than two weeks (Figure 1)

In our series, recurrent haemoptysis occurred within 2 weeks in 14 (9.9\%) of 141 patients after undergoing BAE; 11 (7.8\%) patients from the $\mathrm{TB}+$ Comorbid group and $3(2.1 \%)$ patients from Non-TB group (Fig. 1). Among the 11 patients 5 (3.5\%) patients were diagnosed with TB along with DM, 2 (1.4\%) were HIV seropositive and 2 (1.4\%) patients had cardiovascular diseases (CVD) and 2 patients were on dialysis for chronic kidney disease (CKD).
In non-TB group 2 (1.4\%) had bronchiectasis, $1(0.7 \%)$ patient had bronchogenic carcinoma who died before $2^{\text {nd }}$ reembolisation due to excessive blood loss.

Bleeding resolved spontaneously with conservative management before $2^{\text {nd }}$ re-embolisation in 1 patient belonging to $\mathrm{TB}+$ comorbid group (Fig. 1).

8 patients out of 11 in TB + comorbid group underwent second BAE.

2 out of 3 in non-TB patients underwent successful second BAE; 2 patients having tuberculosis and uncontrolled diabetes died within 4 days after undergoing $2^{\text {nd }}$ bronchial artery embolisation. 
Rest of the $2(1.4 \%)$ in $\mathrm{TB}+$ comorbid group were referred to surgery (Fig. 1).

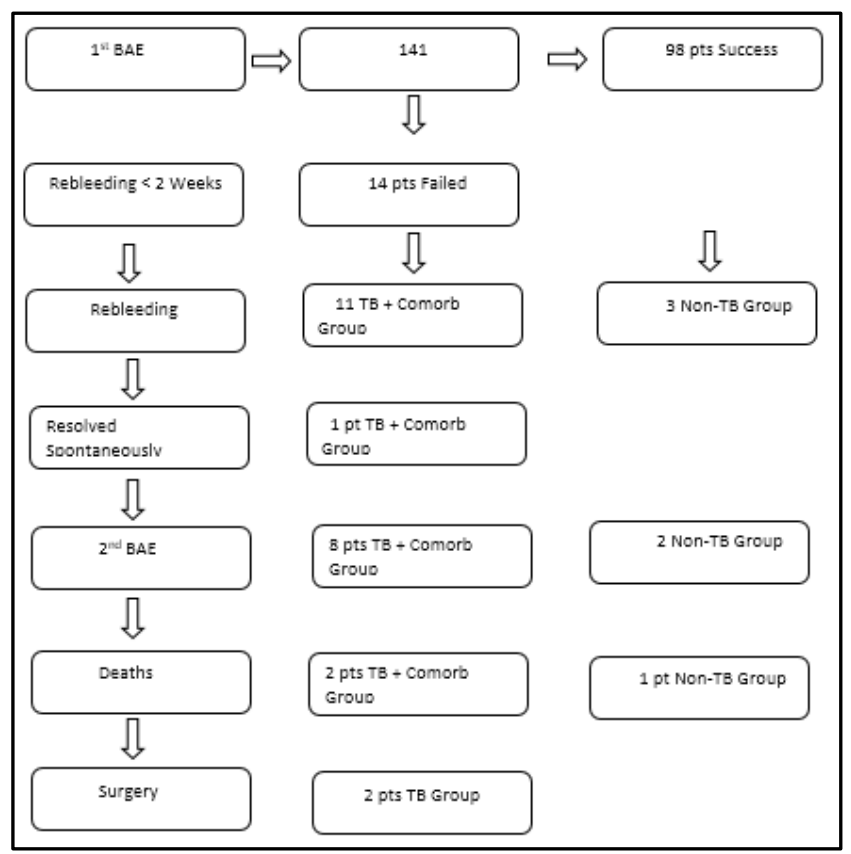

Figure 1. Less than Two Weeks

\section{Within 2 Weeks to 1 Month (Figure 2)}

7 (4.9\%) patients from TB + comorbid group, $1(0.7 \%)$ patient from TB group and $1(0.7 \%)$ patient from non-TB group started rebleeding. Among TB + comorbid group 2 (1.4\%) patients were diagnosed of having HIV, $1(0.7 \%)$ patient suffering with chronic liver disease, $3(2.1 \%)$ patients had diabetes mellitus (Fig. 2); 1 patient in non-TB group having bronchogenic carcinoma underwent second successful embolisation; one TB patient without any comorbid risk factors underwent successful re-embolisation; one patient having tuberculosis with diabetes mellitus died before second embolisation.

Two patients were referred for surgery. Remaining 4 (3.5\%) patients from $\mathrm{TB}+$ Comorbid group (Fig. 2) underwent second BAE; one patient (HIV + TB) died after second BAE.

\section{Within 1 Month - 3 Months (Figure 3)}

$7(4.9 \%)$ patients had recurrent haemoptysis between $1^{\text {st }}$ $3^{\text {rd }}$ month of embolisation; 1 out of 7 patients was from TB group, 4 from TB + Comorbid group and 2 from non-TB group. Haemoptysis in 1 patient (TB group) resolved spontaneously and in 1 patient (non-TB group) resolved with successful antibiotic treatment.

Two patients with diabetes mellitus, 1 patient on immunosuppressant drugs and 1 patient suffering from HIV along with tuberculosis underwent $2^{\text {nd }}$ embolisation; 1 patient from TB + Comorbid group and 1 patient from non-TB died after $2^{\text {nd }}$ re-embolisation (Fig. 3).

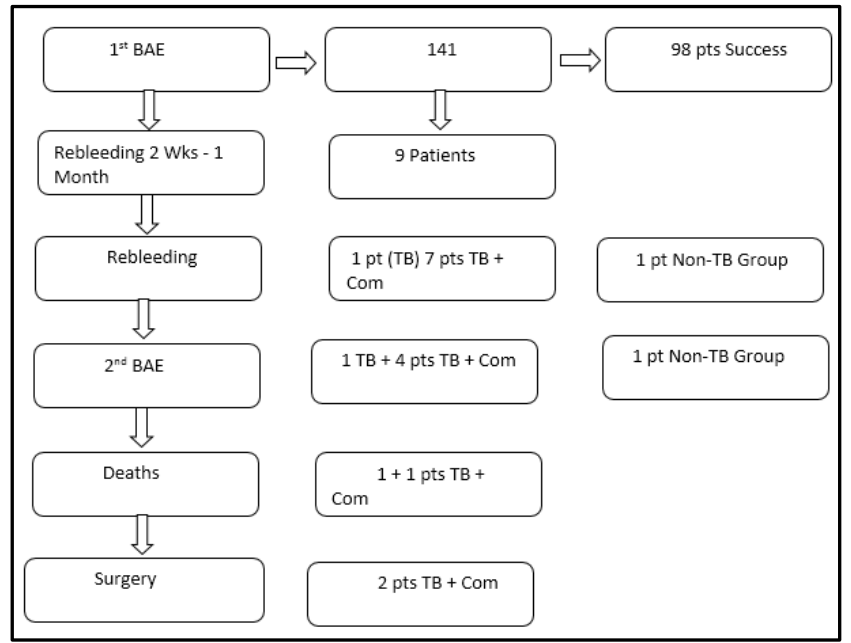

Figure 2. Two Weeks to One Month

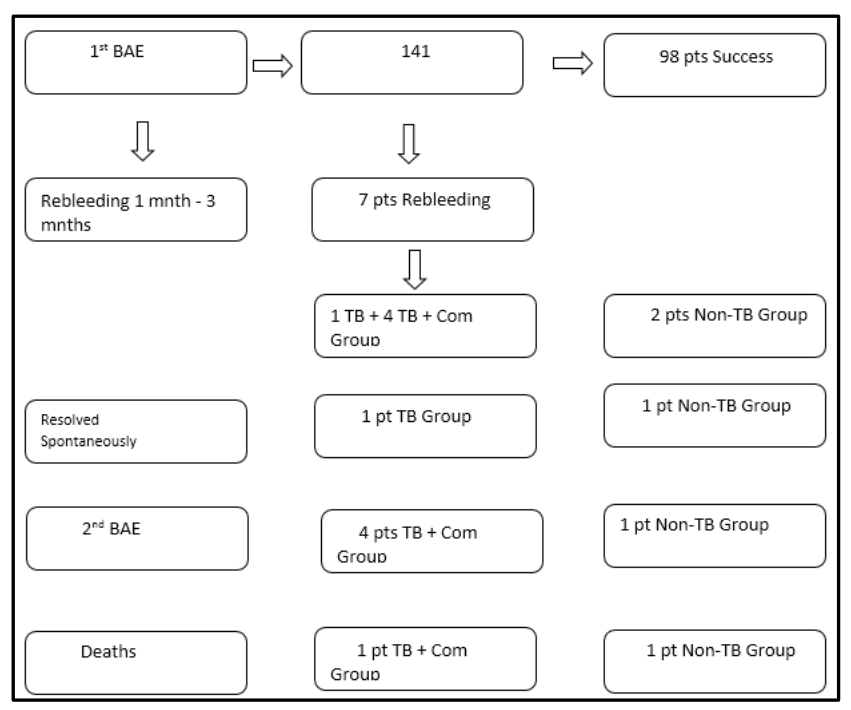

Figure 3. One Month - Three Months

\section{Months - 6 Months}

3 patients developed rebleeding, 2 from $\mathrm{TB}+$ Comorb group and 1 from non-TB group; 1 patient from TB + Comorb group with uncontrolled diabetes mellitus along with sepsis was referred for surgical management. The remaining patients were re-embolised and followed up successfully upto two years uneventfully.

\section{Months - 12 Months}

One patient in TB + Comorb with chronic kidney disease (CKD) started rebleeding and died before the second embolisation procedure; one patient in TB + Comorb and one from non-TB were successfully re-embolised after rebleeding.

\section{Year - 2 Years}

7 patients came with recurrent bleeding; 1 from TB group, 5 from TB + Comorb and 1 from non-TB group. Among the 5 patients, 1 patient was on immunosuppressant drugs, 2 patients with DM, 1 patient with HIV and 1 patient with cirrhosis of liver along with pulmonary tuberculosis.

Patient with cirrhosis of liver died before $2^{\text {nd }}$ BAE; 1 patient having tuberculosis and HIV co-infection underwent surgical treatment. Remaining 5 patients underwent reembolisation successfully. 


\begin{tabular}{|c|c|c|c|c|c|c|c|c|}
\hline \multicolumn{2}{|c|}{ Group } & \multirow{2}{*}{$\frac{<2 \text { wks }}{14}$} & \multirow{2}{*}{\begin{tabular}{|c|}
$2 \mathrm{wks}-1 \mathrm{mn}$ \\
9
\end{tabular}} & \multirow{2}{*}{$\frac{1-3 \mathrm{mn}}{7}$} & \multirow{2}{*}{$\frac{3-6 \mathrm{mn}}{3}$} & \multirow{2}{*}{$\frac{6-1 \mathrm{yr}}{3}$} & \multirow{2}{*}{$\frac{1-2 y r}{7}$} & \multirow[t]{2}{*}{ P value } \\
\hline \multirow{4}{*}{ Rebleeding } & Total & & & & & & & \\
\hline & TB Alone & & 1 & 1 & & & 1 & \\
\hline & TB + Comorbid & 11 & 7 & 4 & 2 & 2 & 5 & $\mathrm{P}<0.05$ \\
\hline & Non-TB & 03 & 1 & 2 & 1 & 1 & 1 & \\
\hline \multirow{2}{*}{ Resolved } & TB Alone & & & 1 & & & & \\
\hline & TB + C:NTB & 01 & & 1 & & & & \\
\hline \multirow{3}{*}{$\begin{array}{c}\text { Death before } \\
2^{\text {nd }} \text { BAE }\end{array}$} & TB Alone & & & & & & & \\
\hline & TB + Comorbid & 01 & 1 & & & & 1 & $\mathrm{P}<0.05$ \\
\hline & Non-TB & & & & & & & \\
\hline \multirow{4}{*}{$2^{\text {nd }} \mathrm{BAE}$} & Total & 10 & 6 & 5 & 2 & 2 & 5 & \\
\hline & TB Alone & & 1 & & & & 1 & \\
\hline & TB + Comorbid & 8 & 4 & 4 & 1 & 1 & 3 & $\mathrm{P}<0.05$ \\
\hline & Non-TB pts. & 2 & 1 & 1 & 1 & 1 & 1 & \\
\hline \multirow{4}{*}{$\begin{array}{c}\text { Total } \\
\text { Deaths }\end{array}$} & Total & 3 & 2 & 2 & & 1 & 1 & \\
\hline & TB Alone & & & & & & & \\
\hline & TB + Comorbid & 2 & 2 & 1 & & 01 & 1 & $\mathrm{P}<0.05$ \\
\hline & Non-TB & 1 & & 1 & & & & \\
\hline Surgery & All Groups & 2 & 2 & & 1 & & 1 & \\
\hline \multicolumn{9}{|c|}{ Table 2. Events that occurred Post BAE Procedure } \\
\hline
\end{tabular}

\section{DISCUSSION}

Haemoptysis was immediately stopped or markedly reduced in 98 patients $(69.5 \%)$ after first bronchial artery embolisation; $30(21.2 \%)$ patients subsequently underwent second bronchial artery embolisation. The overall success of bronchial artery embolisation in our study was $85.1 \%$.

\begin{tabular}{|c|c|c|c|c|}
\hline $\begin{array}{c}\text { Treatment } \\
\text { Arm }\end{array}$ & $\begin{array}{c}\text { Control of } \\
\text { Haemoptysis }\end{array}$ & No Control & $\begin{array}{c}\text { Total } \\
\text { Rows }\end{array}$ & P value \\
\hline PTB & 06 & 03 & 09 & \\
\hline TB + Comorb & 15 & 31 & 46 & $<0.05$ \\
\hline Non-TB & 77 & 09 & 86 & \\
\hline $\begin{array}{c}\text { Total } \\
\text { Columns }\end{array}$ & $\mathbf{9 8 ( 6 9 . 5 \% )}$ & $\mathbf{4 3 ( 3 0 . 4 \% )}$ & $\mathbf{1 4 1}$ & \\
\hline \multicolumn{4}{|c|}{$\begin{array}{c}\text { Table 3. Control of Haemoptysis among } \\
\text { the Three Groups of People }\end{array}$} \\
\hline
\end{tabular}

The chi-square statistic is 45.856. The p-value is < 0.00001 . The result is significant at $\mathrm{p}<.05$.

Among the 141 patients, 43 (29.5\%) experienced recurrence of bleeding during the follow-up period. Table 3 summarises the statistical results of the three groups. Among 141 patients final disease activity was classified as active TB in 9 (6.3\%), TB along with comorbid conditions in 46 (32.6\%) and non-tuberculosis aetiology in 86 (60.1\%).

Control of bleeding is more common in non-TB and PTB patients when compared to the pulmonary tuberculosis along with co-morbid risk factors. These co-morbid risk factors are the main reason for recurrence of haemoptysis after BAE.

In most of the studies, success of BAE ranges from 73 $99 \% .14,15$ In our study, the success of BAE was $69.5 \%$ after $1^{\text {st }}$ BAE; $85.1 \%$ success after 2 BAE. This is the first study to detect the role of co-morbid risk factors on BAE.

Primary Outcome: Cumulative Recurrent Bleeding Free Rate

Using Kaplan-Meier survival analysis, the bleeding free survival rates were calculated and shown in the following Figure 4.
The recurrence of bleeding was taken as event (1) whereas death or lost for followup was taken as censor (0) for 24 months of followup of all patients after the procedure.

Cumulative haemoptysis free survival rate among TB + Comorb group after BAE were $64.4 \%, 55.2 \%$ and $41.2 \%$ in 6 , 12 and 24 months respectively; whereas in non-tuberculous disease it was $81.3 \%, 77.1 \%$ and $68.1 \%$ in 6,12 and 24 months respectively. In tuberculosis alone without any risk factors it was $98.1 \%, 91.2 \%$ and $88.1 \%$ in 6,12 and 24 months respectively. Table 4 shows cumulative haemoptysis control rates in all the three groups.

Disease free survival (DFS) as in our study haemoptysis recurrence free duration (RFD) analysis was done using Kaplan-Meier survival probability.

\begin{tabular}{|c|c|c|c|}
\hline Group & 6 Months & 12 Months & 24 Months \\
\hline Tuberculosis alone & $98.1 \%$ & $91.2 \%$ & $88.1 \%$ \\
\hline TB + Comorb & $64.4 \%$ & $55.2 \%$ & $41.2 \%$ \\
\hline Non-TB & $81.3 \%$ & $77.1 \%$ & $68.1 \%$ \\
\hline \multicolumn{2}{|c|}{ Table 4. The Overall Cumulative Rate of } \\
Haemoptysis Recurrence Free Duration (RFD) \\
\hline
\end{tabular}

\begin{tabular}{|c|c|c|}
\hline & $\begin{array}{c}\text { Univariate (Mean) RFD } \pm \\
\text { SE (Days) }\end{array}$ & Log-Rank \\
\hline TB Alone & 1173.04 & $\mathrm{P}<0.05$ \\
\hline TB + Comorb & 698.19 & \\
\hline Non-TB & 878.01 & \\
\hline \multicolumn{2}{|c|}{ Table 5. Univariate Analysis of } \\
Haemoptysis Recurrence Free Duration \\
\hline
\end{tabular}

\begin{tabular}{|c|c|c|c|}
\hline Characteristics & $\begin{array}{c}\text { Multivariate } \\
\text { Hazard Ratio }\end{array}$ & $\mathbf{9 5 \%}$ CI & P value \\
\hline $\begin{array}{c}\text { Smoking } \geq 30 \text { pack- } \\
\text { years }\end{array}$ & HR 2.157 & $1.243-4.581$ & $<0.05$ \\
\hline $\begin{array}{c}\text { anticoagulant } \\
\text { medications }\end{array}$ & HR 2.103 & $1.233-2.134$ & $<0.05$ \\
\hline Age $\geq 45$ years & HR 2.192 & $1.335-3.846$ & $<0.05$ \\
\hline $\begin{array}{c}\text { Table 6. Multivariate Analysis of Various Risk Factors on } \\
\text { Haemoptysis Recurrence Free Duration }\end{array}$ \\
\hline
\end{tabular}


The Table 4 shows a statistical difference among the three groups $(\mathrm{P}<0.05)$, especially in cases of $\mathrm{TB}+$ comorbid conditions where the recurrence of rebleeding were statistically higher than the rest of the group and univariate analysis shown in Table 5.

\section{Secondary Outcome: Mortality Rate}

Kaplan-Meier survival analysis was used to measure the univariate analysis of mortality among all the three groups. Mortality rate was significantly high in $\mathrm{TB}+$ Comorb group when compared to the rest of the groups $(\mathrm{p}=0.05)$.

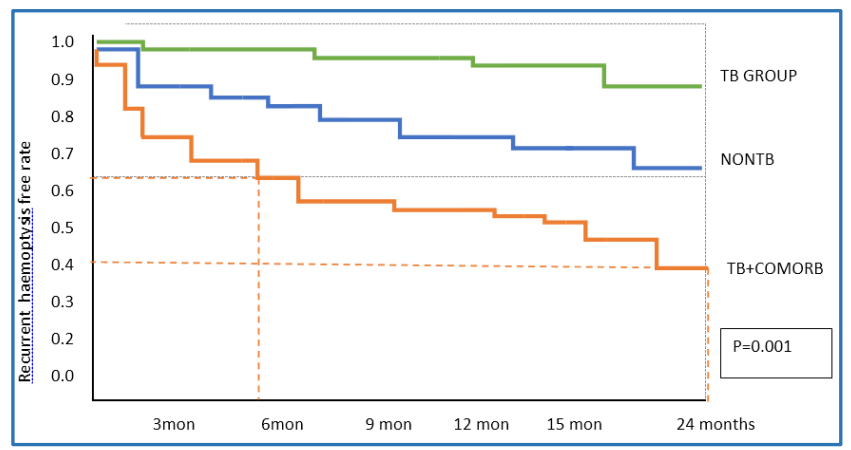

Analysis of parameters influencing on recurrent haemoptysis and mortality

The following parameters namely

1. Age $\geq 45$ years

2. Smoking more $\geq 10$ pack years (py).

3. Smoking more $\geq 20$ pack years.

4. Smoking more $\geq 30$ pack years.

5. Male gender.

6. Anti-coagulant medications were analysed.

Cox regression univariate analysis for these parameters were done for the calculation of recurrence-free rate and survival time. Among these parameters age $\geq 45$ years, smoking $\geq 20$ pack years, smoking $\geq 30$ pack years, male gender and anticoagulant medications showed ( $p<0.05)$ statistical difference. These parameters were checked with cox regression multivariate analysis.

In multivariate analysis smoking $\geq 30$ pack-years (HR 2.157, 95\% CI $1.243-4.581, \mathrm{P}=0.003)$, anticoagulant medications (HR 2.103, 95\% CI $1.233-2.134$, P < 0.002) were associated with recurrent haemoptysis, whereas age $\geq 45$ years (HR 2.192, 95\% CI 1.335 - 3.846, P= 0.004) was associated with mortality in multivariate analysis (Table 6).

Gender, smoking $\geq 10$ pack years and smoking $\geq 20$ pack years were not associated with any statistical significance in Cox regression multivariate analysis.

\section{CONCLUSION}

Prognosis of the TB patients without comorbid risk factors were good when compared to TB along with risk factors for BAE for massive haemoptysis. The risk factors namely diabetes mellitus (DM), human immunodeficiency virus (HIV), chronic liver diseases, chronic renal diseases and coronary artery diseases, not only play an important role in the activation of latent infection, but also causes increased mortality in these patients. So these risk factors namely pulmonary tuberculosis, diabetes mellitus, chronic liver disease, chronic renal diseases and HIV are the main comorbidities in these patients increasing the risk of recurrent haemoptysis and mortality of patients undergoing BAE for massive haemoptysis.

\section{REFERENCES}

[1] Balter MS. Hemoptysis. In: Irwin RS, Curley FJ, Grossman RF. eds. Diagnosis and treatment of symptoms of the respiratory tract. Armonk, NY: Futura Publishing Company Inc., 1997:155-97.

[2] Fraser RS, Pare P, Pare PD. Diseases of the chest. Philadelphia, PA: Saunders 1988:394-6.

[3] Colice GL. Hemoptysis. Three questions that can direct management. Postgrad Med 1996;100(1):227-36.

[4] Corey R, Hla KM. Major and massive hemoptysis: reassessment of conservative management. Am J Med Sci 1987;294(5):301-9.

[5] Baum GL, Wolinsky E. Textbook of pulmonary diseases. Vol. 1. $5^{\text {th }}$ edn. Boston: Little Brown and Co., 1994:248-50.

[6] Szidon JP, Fishman AP. Approach to the pulmonary patient with respiratory signs and symptoms: pulmonary diseases and disorders. $2^{\text {nd }}$ edn. New York: McGraw-Hill 1988:346-51.

[7] Advanced trauma life support. Chicago, IL, American College of Surgeons 1993:77-86.

[8] Yoon W, Kim JK, Kim YH, et al. Bronchial and nonbronchial systemic artery embolization for life threatening hemoptysis: a comprehensive review. Radiographics 2002;22(6):1395-409.

[9] Jean-Baptiste E. Clinical assessment and management of massive hemoptysis. Crit Care Med 2000;28(5):1642-7.

[10] Bruzzi JF, Re'my-Jardin M, Delhaye D, et al. Multidetector row CT of hemoptysis. Radiographics 2006;26(1):3-22.

[11] Garzon AA, Gourin A. Surgical management of massive hemoptysis: a ten-year experience. Ann Surg 1978;187(3):267-71.

[12] Shigemura N, Wan IY, Yu SC, et al. Multidisciplinary management of life-threatening massive hemoptysis: a 10-year experience. Ann Thorac Surg 2009;87(3):849-53.

[13] Swanson KL, Johnson CM, Prakash UB, et al. Bronchial artery embolization: experience with 54 patients. Chest 2002;121(3):789-95.

[14] Poyanli A, Acunas B, Rozanes I, et al. Endovascular therapy in the management of moderate and massive haemoptysis. Br J Radiol 2007;80(953):331-6.

[15] Haponik EF, Fein A, Chin R. Managing life-threatening hemoptysis: has anything really changed? Chest 2000;118(5):1431-5.

[16] Park HS, Kim YI, Kim HY, et al. Bronchial artery and systemic artery embolization in the management of primary lung cancer patients with hemoptysis. Cardiovasc Interv Radiol 2007;30(4):638-43.

[17] Lee S, Chan JW, Chan SC, et al. Bronchial artery embolisation can be equally safe and effective in the management of chronic recurrent haemoptysis. Hong Kong Med J 2008;14(1):14-20. 
[18] Dwivedi MK, Pal RK, Borkar PB. Management of severe hemoptysis due to pulmonary tuberculosis by bronchial artery embolization. Indian Journal of Radiology and Imaging 1999;9(4):165-8.

[19] Gaziano TA, Bitton A, Anand S, et al. Growing epidemic of coronary heart disease in low-and middle-income countries. Curr Probl Cardiol 2010;35(2):72-115.
[20] Wurie HR, Cappuccio FP. Cardiovascular disease in low-and middle-income countries: an urgent priority. Ethn Health 2012;17(6):543-50.

[21] Epstein SE, Zhu J, Najafi AH, et al. Insights into the role of infection in atherogenesis and in plaque rupture. Circulation 2009;119(24):3133-41. 